\title{
A SNARE Complex Containing Syntaxin 3 Is Present in Ribbon Synapses of the Retina
}

\author{
Catherine W. Morgans, ${ }^{1,2}$ Johann H. Brandstätter, ${ }^{1}$ Joseph Kellerman, ${ }^{3}$ Heinrich Betz, ${ }^{2}$ and Heinz Wässle ${ }^{1}$ \\ Departments of ${ }^{1}$ Neuroanatomy and ${ }^{2}$ Neurochemistry, Max Planck Institute for Brain Research, 60528 Frankfurt, \\ Germany, and 3Max Planck Institute for Biochemistry, 82152 Martinsried, Germany
}

In contrast to conventional synapses, which release neurotransmitter transiently, ribbon synapses formed by photoreceptors and bipolar cells of the retina release neurotransmitter continuously and modulate the rate in response to light. Both modes of release are mediated by synaptic vesicles but probably differ in the regulation of docking and fusion of synaptic vesicles with the plasma membrane. We have found that syntaxin 1, an essential component of the core fusion complex in conventional synapses, is absent from ribbon synapses of the retina, raising the possibility that these synapses contain a different type of syntaxin or syntaxin-like protein. By immunoprecipitating syntaxin 1-depleted retina and brain extracts with a SNAP-25 antibody and microsequencing the precipitated proteins, syntaxin 3 was detected in retina complexed with SNAP-25, synaptobrevin, and complexin. Using an antisyntaxin 3 antiserum, syntaxin 3 was demonstrated to be present at high levels in retina compared to brain. Immunofluorescent staining of rat retina sections confirmed that syntaxin 3 is expressed by photoreceptor and bipolar cells in the retina. Thus, in the retina, expression of syntaxin 3 is correlated with ribbon synapses and may play a role in the tonic release of neurotransmitter.

Key words: retina; ribbon synapse; synaptic vesicle exocytosis; SNARE complex; syntaxin 3; SNAP-25; complexin
In mammals, ribbon synapses occur in retinal photoreceptors and bipolar cells, saccular and vestibular hair cells, and pinealocytes (Devries and Baylor, 1993). In contrast to conventional synapses, which release neurotransmitter transiently, ribbon synapses release neurotransmitter continuously and at a high rate (Devries and Baylor, 1993).

Although a majority of proteins in the synaptic vesicle cycle appear to be conserved between ribbon and conventional synapses, a few striking differences have been observed in ribbon synapses that may be important for high rates of tonic neurotransmitter release. For example, ribbon synapses lack synapsins (Mandell, 1990; Mandell et al., 1992), synaptic vesicle-associated proteins found in all conventional synapses and implicated in synaptic vesicle recruitment to the active zone (Pieribone et al., 1995; Rosahl, 1995). In ribbon synapses, recruitment of synaptic vesicles is probably the function of the synaptic ribbons, electron-dense structures above the active zones to which synaptic vesicles are tethered (Rao-Mirotznik et al., 1995).

The calcium channels that regulate calcium influx into the nerve terminals are also different. Conventional synapses contain mainly N-, P-, and Q-type channels (Takahashi, 1993; Turner, 1993; Wheeler et al., 1994) that rapidly inactivate in response to sustained depolarization. Fish and amphibian photoreceptor and bipolar cells (Heidelberger and Matthews, 1992; Rieke and Schwartz, 1994) and chick hair cells (Fuchs et al., 1990) contain L-type channels that inactivate very slowly, if at all, in response to similar depolarizations.

\footnotetext{
Received June 17, 1996; revised Aug. 9, 1996; accepted Aug. 13, 1996.

This study was supported by Fonds der Chemischen Industrie. We thank Anja Leihkauf for expert technical assistance and Rowland Taylor, Joachim Kirsch, and Vincent O'Connor for critically reading this manuscript.

Correspondence should be addressed to Catherine W. Morgans, Max Planck Institut für Hirnforschung, Neuroanatomische Abteilung, Deutschordenstrasse 46, 60528 Frankfurt, Germany.

Copyright (C) 1996 Society for Neuroscience $0270-6474 / 96 / 166713-09 \$ 05.00 / 0$
}

A third notable difference is the absence of syntaxin 1 in ribbon synapses (Ullrich, 1994; Brandstätter et al., 1996). In current models of synaptic vesicle exocytosis, two presynaptic plasma membrane proteins, syntaxin $1(35 \mathrm{kDa})$ and SNAP-25 (synaptosomal-associated protein of $25 \mathrm{kDa}$ ), interact to form a high-affinity receptor for synaptobrevin $(18 \mathrm{kDa})$, an integral membrane protein of synaptic vesicles (Söllner, 1993). This ternary "core" complex, referred to as the SNARE (SNAP receptor) complex, mediates fusion of synaptic vesicles with the plasma membrane through the sequential binding of two cytosolic proteins, $\alpha$-SNAP (soluble NSF attachment protein) and NSF $(N$ ethylmaleimide-sensitive factor). ATP hydrolysis by NSF is postulated to activate the SNARE complex, allowing fusion to proceed after detection of calcium (Söllner, 1993; Pellegrini et al., 1995; Südhof, 1995).

Underscoring its central role in the fusion reaction, syntaxin 1 has been demonstrated in vitro to bind to many of the other proteins involved in neurotransmitter release. These include calcium channels (Yoshida et al., 1992; O'Connor, 1993; Sheng et al., 1994; Bezprozvanny et al., 1995), synaptotagmin (Li et al., 1995; Kee and Scheller, 1996), n-Sec1 (Hata et al., 1993; Garcia et al., 1994; Pevsner et al., 1994b), and complexins 1 and 2 (McMahon et al., 1995), as well as synaptobrevin and SNAP-25.

As a first step in understanding the exocytotic machinery of ribbon synapses, we have attempted to identify a ribbon synapse form of syntaxin. Here we report the presence of syntaxin 3 in ribbon synapses of the retina and show that it forms a SNARE complex with SNAP-25, synaptobrevin, and complexin.

\section{MATERIALS AND METHODS}

Antibodies. The mouse monoclonal antibody against SNAP-25, SMI 81, was purchased from Affiniti Research Products (Nottingham, UK). The mouse monoclonal antibody against syntaxin $1,10 \mathrm{H} 5$, was kindly provided by Dr. M. Takahashi (Mitsubishi Kasei Institute of Life Sciences). The mouse monoclonal antibody against protein kinase $\mathrm{C}$ was from 

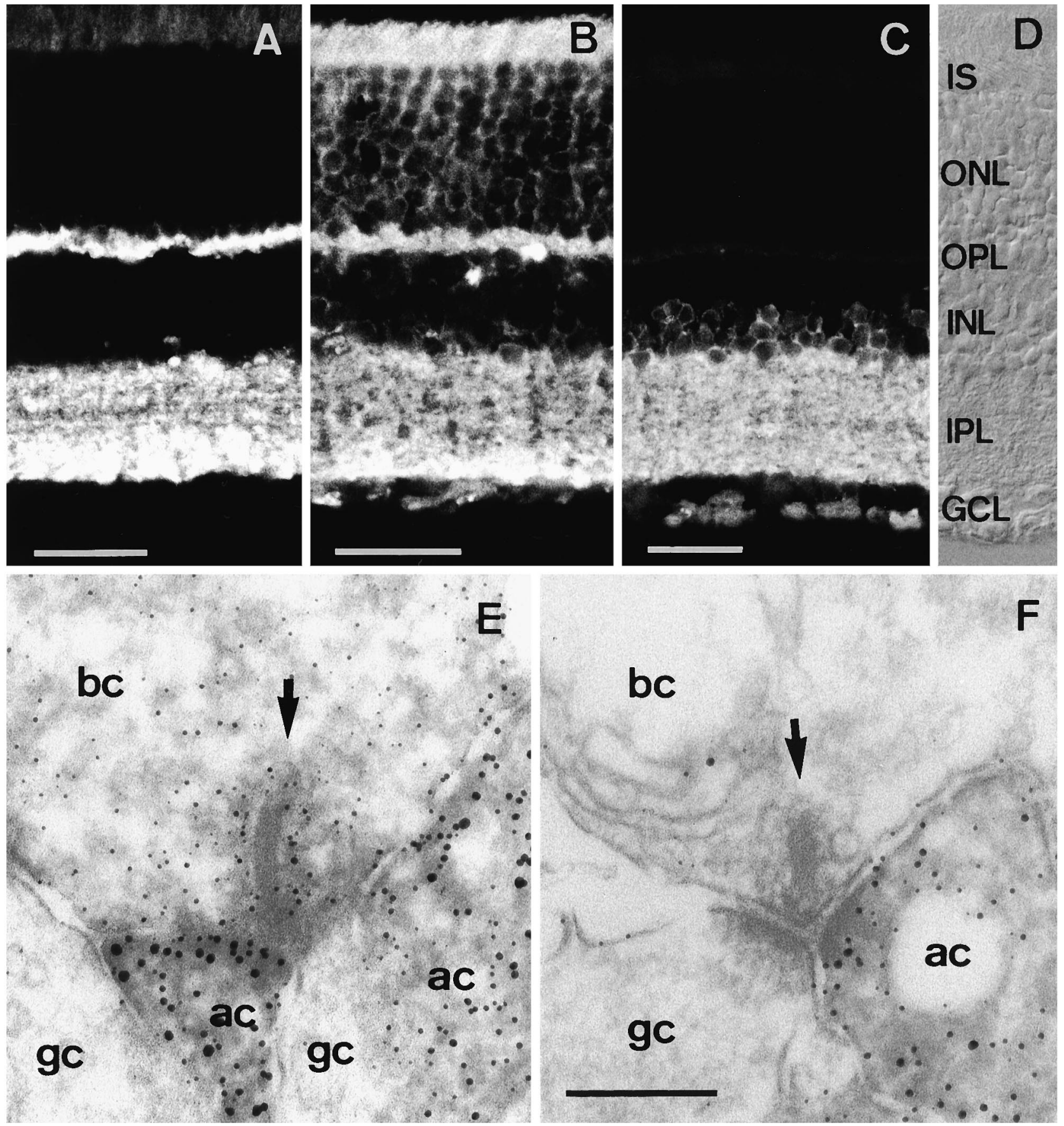

bc

Figure 1. Vertical cryostat sections through rat retina labeled with antibodies against different synaptic proteins. Synaptobrevin $(A)$ and SNAP-25 $(B)$ are both present in the OPL and IPL. $C$, Syntaxin 1 is present only in the INL and IPL. $D$, Nomarski image showing the retinal layers. Electron microscopic localization of $(E)$ SNAP-25 and $(F)$ syntaxin 1 in the rat retina. Whereas SNAP-25 is present at all synapses of all neurons in the retina, syntaxin 1 is present only in amacrine cells that form conventional synapses. $I S$, Inner segments; $O N L$, outer nuclear layer; $O P L$, outer plexiform layer; $I N L$, inner nuclear layer; $I P L$, inner plexiform layer; $G C L$, ganglion cell layer; $b c$, bipolar cell; $a c$, amacrine cell; $g c$, ganglion cell. Scale bars: $A-C$, $30 \mu \mathrm{m}$ (scale bar in $C$ also applies to $D$ ); $E, F, 0.2 \mu \mathrm{m}$ (shown in $F$ ).

Amersham (Arlington Heights, IL). Two rabbit polyclonal antibodies against synaptobrevin 2/VAMP II were used. One (see Fig. $2 B$ ) was kindly provided by Dr. M. Takahashi. The other (see Fig. $4 B$ ) was the generous gift of Dr. R. Scheller (Stanford University, Stanford, CA). The following secondary antibodies were used: goat anti-mouse IgG conjugated to carboxymethylindocyanine (CY3; Dianova, Hamburg, Germany), goat anti-rabbit IgG conjugated to fluorescein isothiocyanate (FITC; Dianova), goat anti-mouse IgG conjugated to FITC (Dianova), and donkey anti-sheep IgG conjugated to CY3 (Dianova).

Light microscopic immunocytochemistry. Vertical rat retina sections were prepared as described previously (Brandstätter et al., 1996). The sections were incubated $1 \mathrm{hr}$ in blocking solution $[10 \%(\mathrm{v} / \mathrm{v})$ normal goat serum (NGS), $1 \%(\mathrm{w} / \mathrm{v})$ BSA, $0.5 \%(\mathrm{v} / \mathrm{v})$ Triton X-100 in PBS] followed by an overnight incubation in the primary antibody diluted in incubation solution [3\% (v/v) NGS, $1 \%(\mathrm{w} / \mathrm{v})$ BSA, $0.5 \%(\mathrm{v} / \mathrm{v})$ Triton $\mathrm{X}-100$ in PBS]. The primary antibodies were diluted as follows: SNAP-25 (1:10,000), synaptobrevin 2/VAMP II (1:1000), syntaxin 1 (1:1000), syntaxin $3(1: 50)$, and PKC $\alpha$ (1:100). After washing, the sections were incubated for $1 \mathrm{hr}$ in the secondary antibody diluted in incubation solution: 1:1000 for the CY3 conjugates and 1:50 for the 


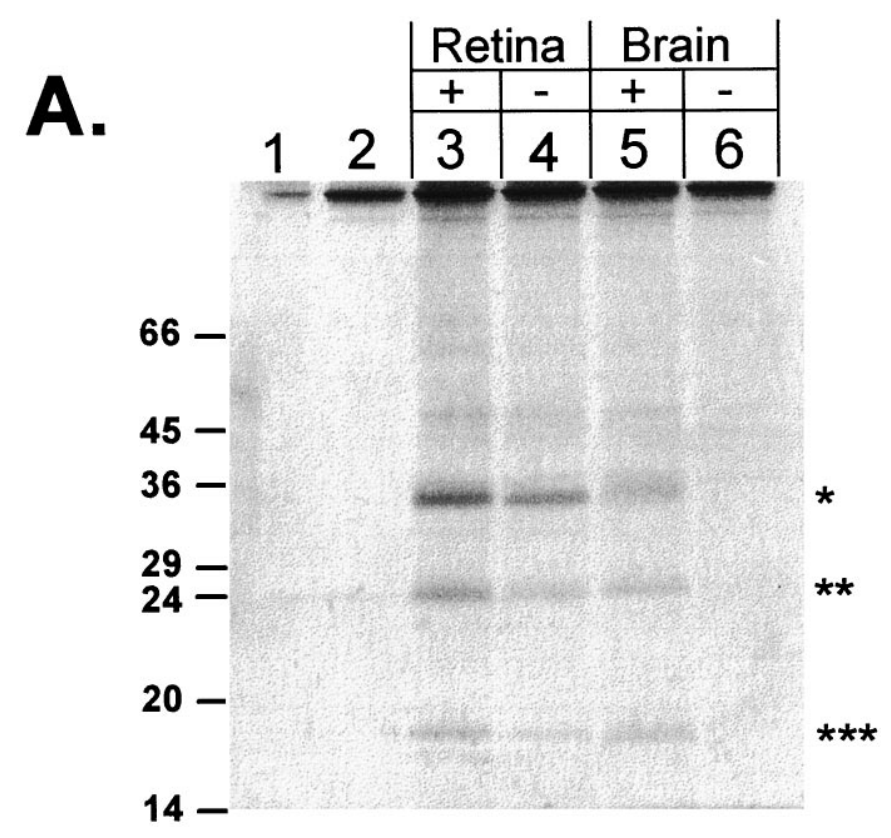

B.

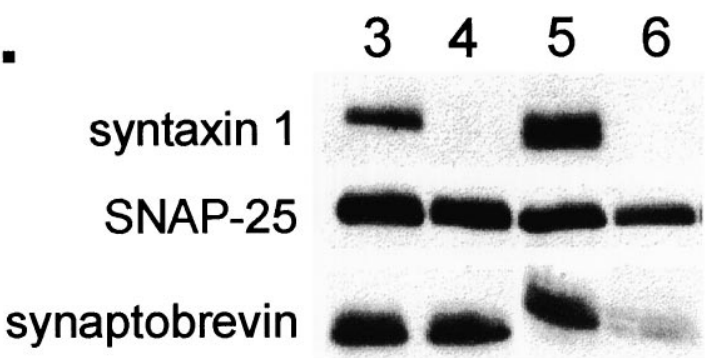

Figure 2. The retina contains a $35 \mathrm{kDa}$ protein that binds to SNAP-25 but does not react with antibodies against syntaxin 1 . Syntaxin 1-depleted (-) and nondepleted $(+)$ retina and brain extracts were immunoprecipitated with a SNAP-25 antibody. The SNAP-25 immunoprecipitates are from: 1, whole retina extract to which no SNAP-25 antibody was added; 2, I.P. buffer alone; 3 , nondepleted retina extract; 4 , syntaxin 1-depleted retina extract; 5, nondepleted brain extract; and 6, syntaxin 1-depleted brain extract. $A$, The precipitated proteins were separated by SDS-PAGE, and then the gel was stained with Coomassie blue. The position of the $35 \mathrm{kDa}$ bands is indicated by *, the $25 \mathrm{kDa}$ bands by **, and the $18 \mathrm{kDa}$ bands by ***. The position of size markers are indicated on the left. B, Samples 3-6 were run on a duplicate gel, electrophoretically transferred to nitrocellulose, and immunoblotted with antibodies against syntaxin 1, SNAP-25, and synaptobrevin.

FITC conjugates. The sections were washed again and then coverslipped with Mowiol (Hoechst, Frankfurt, Germany). For the syntaxin 3 immunocytochemistry, normal horse serum replaced NGS in the blocking and antibody incubation solutions. For double-labeling experiments, sections were first incubated in anti-syntaxin 3 overnight at $37^{\circ} \mathrm{C}$ and then with anti-protein kinase $\mathrm{C}$ for $1 \mathrm{hr}$ at $37^{\circ} \mathrm{C}$. After washing, the sections were incubated with a mixture of anti-sheep and anti-mouse secondary antibodies conjugated to CY3 and FITC, respectively, and processed as for single-labeling experiments.

Electron microscopic immunocytochemistry. The procedure for electron microscopic immunocytochemistry has been described previously (Brandstätter et al., 1996).

Isolation of syntaxin 3 from retina. Homogenized bovine retinas or rat brain were suspended in an equal volume of I.P. buffer [2\% (v/v) Triton $\mathrm{X}-100,20 \mathrm{~mm}$ HEPES, pH 7.0, 1\% (v/v) glycerol, $100 \mathrm{~mm} \mathrm{KCl,} 0.025 \%$ (w/v) sodium azide] containing $0.25 \mathrm{~mm}$ phenylmethanesulfonylfluoride (Sigma, Deisenhofen, Germany) and incubated on ice for $30 \mathrm{~min}$. Insoluble material was pelleted by centrifugation at $20,000 \times g$ for 15 $\min$ at $4^{\circ} \mathrm{C}$. The supernatants were removed and divided in half. One-half of both the brain and the retina extracts, containing $200 \mu \mathrm{g}$ of protein, was depleted of syntaxin 1 by the addition of $2.5-5 \mu \mathrm{l}$ of $10 \mathrm{H} 5$ antibody followed by an incubation overnight at $4^{\circ} \mathrm{C}$. Protein G-Sepharose (Sigma; $25 \mu \mathrm{l}$ ) was then added before an additional $2 \mathrm{hr}$ incubation at $4^{\circ} \mathrm{C}$ with mixing. The Sepharose beads were pelleted by a brief centrifugation, and the supernatants were transferred to new tubes. This procedure was repeated on the supernatant three more times. The depletion of syntaxin 1 from the extract was monitored by immunoblotting. No immunoreactive syntaxin 1 remained in either the brain or the retina extracts after the fourth immunoprecipitation. Aliquots of both the syntaxin 1-depleted and the whole extracts corresponding to 200 and $100 \mu \mathrm{g}$ of protein from retina and brain, respectively, were diluted to $1 \mathrm{ml}$ with I.P. buffer and then immunoprecipitated with a SNAP-25 antibody. The extracts were incubated at $4{ }^{\circ} \mathrm{C}$ overnight with $2 \mu \mathrm{l}$ of SNAP-25 antibody, followed by gentle mixing for $2 \mathrm{hr}$ at $4^{\circ} \mathrm{C}$ after the addition of $25 \mu \mathrm{l}$ of protein G-Sepharose. The Sepharose beads were washed five times at room temperature with $1 \mathrm{ml}$ of I.P. wash buffer and suspended in $50 \mu \mathrm{l}$ of nonreducing Laemmli sample buffer. The proteins were separated by SDS-PAGE on a $12.5 \%$ acrylamide gel and visualized by Coomassie blue staining or immunoblotting with syntaxin 1, SNAP-25, and synaptobrevin antibodies (Brandstätter et al., 1996).

Protein sequencing. The proteins to be sequenced were blotted onto PVDF membrane and visualized on the membrane by Ponceau $\mathrm{S}$ staining. The protein bands were excised form the membrane, cut into small pieces $(3 \times 3 \mathrm{~mm})$, and incubated with $500 \mu \mathrm{l}$ of $0.2 \%(\mathrm{w} / \mathrm{v})$ polyvinylpyrolidone (PVP 30) in water for $30 \mathrm{~min}$ at room temperature (Patterson, 1994). The supernatant was discarded, and the membrane was washed six times with water and incubated with $0.1 \mathrm{~m} \mathrm{Tris-HCl,} \mathrm{pH}$ $8.0,2 \mathrm{mM} \mathrm{CaCl}_{2}, 10 \%(\mathrm{w} / \mathrm{v})$ acetonitrile, $1 \%(\mathrm{w} / \mathrm{v}) \mathrm{NP} 40$, and $0.5 \mu \mathrm{g}$ of endoproteinase LysC (Boehringer Mannheim, Mannheim, Germany) for $8 \mathrm{hr}$ at $37^{\circ} \mathrm{C}$. The resulting peptides were eluted twice with $0.1 \%$ $(\mathrm{w} / \mathrm{v})$ TFA and again with $10 \%$ (w/v) formic acid, $20 \%(\mathrm{w} / \mathrm{v})$ isopropanol, and $20 \%(\mathrm{w} / \mathrm{v})$ acetonitrile. The supernatants were dried down, and the cleavage mixture was separated on a reverse-phase column supersphere 60RP select B (Merck, Darmstadt, Germany; $2 \times 125$ $\mathrm{mm}^{2}$ ). Solvent A was $0.1 \%(\mathrm{w} / \mathrm{v})$ TFA, and solvent B was $0.1 \%(\mathrm{w} / \mathrm{v})$ TFA in acetonitrile. The gradient was $0-60 \%$ B over a period of $60 \mathrm{~min}$ at a flow rate of $300 \mu \mathrm{l} / \mathrm{min}$. The detection wavelength was $206 \mathrm{~nm}$. The peptides were sequenced (Edman and Begg, 1967) on a pulsed liquid phase sequencer Procise 493 (Applied Biosystems, Foster City, CA) according to the manufacturer's instructions.

Syntaxin 3 antiserum production. The following procedure was performed by Chiron Mimotopes (Melbourne, Australia). A peptide corresponding to amino acids $9-23$ of syntaxin 3 was synthesized and coupled through an additional $\mathrm{N}$-terminal cysteine to diphtheria toxoid (DT). The peptide-DT conjugate was resuspended in water, emulsified with complete Freund's adjuvant, and injected intramuscularly into a sheep. A second, similar immunization followed 2 weeks later, using incomplete Freund's adjuvant. Serum was prepared by heating the collected blood at $37^{\circ} \mathrm{C}$ for $30 \mathrm{~min}$, then chilling it at $4^{\circ} \mathrm{C}$ for $15 \mathrm{hr}$, followed by centrifugation. The serum was stored at $-20^{\circ} \mathrm{C}$.

Immunoblotting. Retina and brain membranes were solubilized in sample buffer and separated by SDS-PAGE on a $12.5 \%(\mathrm{w} / \mathrm{v})$ acrylamide gel (Laemmli, 1970). The proteins were electrophoretically transferred to nitrocellulose and reacted with antibodies as described previously (Brandstätter et al., 1996). Primary antibodies were used at the following dilutions: syntaxin $1(1: 10,000)$, SNAP-25 $(1: 10,000)$, synaptobrevin $(1: 1000)$, syntaxin 3 (1:1000). Immunoreactivity was revealed with an ECL kit (Amersham) according to the manufacturer's instructions.

\section{RESULTS}

\section{Syntaxin 1 is absent from ribbon synapses in the retina}

The retina contains two synaptic layers: the inner and outer plexiform layers. Synapses in the outer plexiform layer (OPL) are composed almost exclusively of the ribbon synapse-forming terminals of rod and cone photoreceptors. Very few conventional synapses occur in the OPL (Linberg and Fisher, 1986, 1988). Synapses of the inner plexiform layer (IPL) are a mixture of ribbon synapses made by bipolar cells, and conventional synapses made by amacrine cells (Dubin, 1970; Fischer, 1979). 
A.

\begin{tabular}{|c|c|c|}
\hline PEPTIDE & SEQUENCE & IDENTITY \\
\hline $36 \mathrm{kD}$ & $\begin{array}{l}\text { KLYSIILSAPIPEPK } \\
\text { YNEAQVDFRERSK } \\
\text { DIVRLESSIK }\end{array}$ & $\begin{array}{l}\text { syntaxin } 3,100 \% \\
\text { (Bennett, et al., 1993) }\end{array}$ \\
\hline $25 \mathrm{kD}$ & $\begin{array}{l}\text { DAGIRTLVMLDEQG } \\
\text { TRIDEANQRATK }\end{array}$ & $\begin{array}{l}\text { SNAP-25, } 100 \% \\
\text { (Catsicas et al., 1991) }\end{array}$ \\
\hline $18 \mathrm{kD}$ & $\begin{array}{l}\text { KEEERQEALRQEEEERK* } \\
\text { MEAEREAVRQGIRDK* } \\
\text { AALEQPPEGSLT }\end{array}$ & $\begin{array}{c}\text { complexin 1, } 83 \% \\
\text { complexin 2, 90\% } \\
\text { (McMahon, et al., 1995) }\end{array}$ \\
\hline
\end{tabular}

* Sequenced two times.

\section{B.}

Figure 3. A, Amino acid sequences and percent identities of peptides derived from the 35,25 , and $18 \mathrm{kDa}$ proteins immunoprecipitated with the SNAP-25 antibody from syntaxin 1-depleted bovine retina extract. Underlined residues were identified with a lower degree of certainty. $B$, Alignment of the peptide sequences derived from the retina $18 \mathrm{kDa}$ band with the sequences of rat complexins 1 and 2 (McMahon et al., 1995). Amino acids that are not conserved between all sequences are in bold. Amino acids in the retinal $18 \mathrm{kDa}$ band that differ from either or both complexins 1 and 2 are boxed.

\begin{abstract}
Complexin 1: MEFVMKQALGGATKDMGKMLGGDEEKDPDAAKKEEEROEALROAEEERKA 50 $18 \mathrm{Kd}$ band: KEEERQEALRdEEEERK

Complexin 2: MDFVMKQALGGATKDMGKMLGGDEEKDPDAQKKEEERQEALRQQEEERKA 50

Complexin 1: KYAKMEAEREVMROGIRDKYGIKKKEEREAEAQAAMEANSEGSLTRPKKA 100 $18 \mathrm{Kd}$ band: MEAEREAVRQGIRDK AATEQPFEGSLT

Complexin 2: KHARMEAEREKURQQIRDKYGLKKKEEKEAEEKAAIEQFGEGSTRRKKA 100
\end{abstract} 50

Complexin 1: IPPGCGDEPEEEDESILDTVIKYLPGPLQDMFKK 134

Complexin 2: IPAGCGDEEEEEEESILDTVLKYLPGPLQDMFKK 134
To find out whether the absence of syntaxin 1 immunoreactivity is a general feature of ribbon synapses in the retina, we compared the presence of neuronal SNARE proteins in both the IPL and the OPL by light and electron microscopic immunocytochemistry. Rat retina sections were immunolabeled with antibodies against SNAP-25, syntaxin 1, or synaptobrevin. Intense synaptobrevin labeling was detected in both the inner and the outer plexiform layers of the retina (Fig. 1A). The SNAP-25 antibody also strongly labeled the IPL and OPL, as well as the photoreceptor inner segments (Fig. 1B). Like SNAP-25 and synaptobrevin, strong syntaxin 1 staining was observed in the IPL (Fig. $1 C$ ). The syntaxin 1 antibody also labeled the plasma membrane of amacrine cell somata in the inner nuclear layer and the ganglion cell layer, as reported previously (Barnstable et al., 1985). In contrast to SNAP-25 and synaptobrevin, however, labeling for syntaxin 1 was not detected in the outer retina including the OPL (Fig. 1C). These data demonstrate that ribbon synapses of the photoreceptors are immunoreactive for SNAP-25 and synaptobrevin but not syntaxin 1, the third component of the neuronal SNARE complex. Because the IPL contains both conventional and ribbon synaptic terminals, immunoelectron microscopy was performed on rat retina with both the syntaxin 1 and the SNAP-25 antibodies. As reported previously (Brandstätter et al., 1996), we found that syntaxin 1 staining was restricted to amacrine cells, which are the source of conventional synapses, and was never observed in ribbon synapses (Fig. $1 F$ ). In contrast, SNAP-25 labeling was observed in all synapses (Fig. 1E). Thus, we conclude that syntaxin 1 is absent from all ribbon synapses of the retina.

The retina contains a $35 \mathrm{kDa}$, SNAP-25-binding protein distinct from syntaxin 1

We searched for a candidate ribbon synapse form of syntaxin by immunoprecipitating syntaxin 1-depleted retina and brain ex- tracts with an antibody against SNAP-25. First, detergent extracts of rat brain and bovine retina underwent successive immunoprecipitations with a syntaxin 1 antibody until no further syntaxin immunoreactivity could be detected by Western blotting (data not shown). Then aliquots of syntaxin 1-depleted and nondepleted extracts were immunoprecipitated with a SNAP-25 antibody. The immunoprecipitated proteins were separated by nonreducing SDS-PAGE and analyzed by Coomassie blue staining (Fig. $2 A$ ). In both the nondepleted brain and the retina extracts, three major bands of 35,25 , and $18 \mathrm{kDa}$ were immunoprecipitated (Fig. $2 A$, lanes 3,5 ). These bands correspond in size to syntaxin 1, SNAP-25, and synaptobrevin, respectively. After immunodepletion of syntaxin 1, no protein detectable by Coomassie blue staining was immunoprecipitated with the SNAP-25 antibody from brain extract (Fig. $2 A$, lane $6)$, indicating that most of the SNAP-25 in brain can be codepleted with syntaxin 1 . In contrast, SNAP-25 immunoprecipitation from syntaxin 1-depleted retina extract yielded three bands on a Coomassie blue-stained gel (Fig. 2A, lane 4 ) identical in size to those obtained from nondepleted extract (Fig. $2 A$, lane 3).

This result can be attributable either to an incomplete immunodepletion of syntaxin 1 from the retina extract or to the binding of SNAP-25 to a protein of $35 \mathrm{kDa}$ that is distinct from syntaxin 1 . To distinguish between these possibilities, samples on a duplicate gel were transferred to nitrocellulose and reacted with antibodies against SNAP-25, syntaxin 1, and synaptobrevin. SNAP-25 was detected in depleted and nondepleted extracts of both retina and brain. Synaptobrevin immunoreactivity was seen in the nondepleted extracts from both retina and brain and in the depleted retina extract, but not in the depleted brain extract. Apparently, all synaptobrevin in brain, but not retina, was complexed to syntaxin 1 . Syntaxin 1 was detected 
A.

\section{Syntaxin3 Syntaxin1 \begin{tabular}{ll|ll} 
R & B & R & B
\end{tabular}}

66-

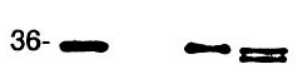

24-

Figure 4. $A$, Syntaxin 3 is present in retina but not brain. Approximately $5 \mu \mathrm{g}$ of membrane protein from rat retina $(R)$ and rat brain $(B)$ was separated by SDS-PAGE and immunoblotted with antibodies specific for either syntaxin 1 or syntaxin 3 . The positions of size markers are indicated on the left. $B$, Syntaxin 3 forms a complex with SNAP-25 and synaptobrevin. Retina extract was immunoprecipitated with either protein G-Sepharose alone $(-)$ or protein $\mathrm{G}-$ Sepharose + anti-syntaxin $3(+)$, followed by immunoblotting the immunoprecipitated material with antibodies against syntaxin 3, SNAP-25, and synaptobrevin.

only in the immunoprecipitates from the nondepleted retina and brain extracts.

We conclude from these data that the $35 \mathrm{kDa}$ protein detected in the syntaxin 1-depleted retina extract by Coomassie blue staining is not syntaxin 1, but fulfills the following criteria expected of a ribbon synapse form of syntaxin: (1) it is enriched in retina compared to brain; (2) it is $35 \mathrm{kDa}$, approximately the same size as other members of the syntaxin family of proteins (Bennett et al., 1993); and (3) it is associated with SNAP-25 and possibly synaptobrevin. Therefore, it seems likely that another SNARE complex occurs in the retina, probably in the photoreceptors and bipolar cells that do not express syntaxin 1 .

\section{The retina expresses a syntaxin 3-containing SNARE complex}

The identity of the proteins composing the retinal SNARE complex was determined by microsequencing. All three proteins immunoprecipitated from the syntaxin 1-depleted bovine retina extract were digested with endoproteinase LysC, and the resulting peptides were microsequenced (Fig. 3). Three sequences of 10,13 , and 15 amino acids were obtained for the 35 $\mathrm{kDa}$ band, and all showed $100 \%$ amino acid identity with regions of rat syntaxin 3 (Fig. $3 A$ ). Two peptide sequences were obtained from the $25 \mathrm{kDa}$ band, both $100 \%$ identical to regions of SNAP-25 (Fig. $3 A$ ). Three peptide sequences of 17, 15, and 12 amino acids were obtained for the $18 \mathrm{kDa}$ band that were 83 and $90 \%$ identical to rat complexins 1 and 2, respectively (Fig. $3 B)$. Although synaptobrevin was detected by immunoblotting (Fig. 2B), no synaptobrevin sequence was obtained. Thus, the retina contains a novel SNARE complex harboring syntaxin 3, SNAP-25, and complexin.

To confirm the presence of syntaxin 3 in the retina, an antiserum was raised against a syntaxin 3 peptide corresponding to an $\mathrm{N}$-terminal domain of the protein that has the lowest sequence homology to syntaxin 1 (Bennett et al., 1993). The specificity of the anti-syntaxin 3 antiserum was demonstrated by Western blotting equal quantities of retina and brain membranes with both anti-syntaxin 1 and anti-syntaxin 3 (Fig. $4 A$ ). In brain, antisyntaxin 1 recognized a doublet of 34 and $35 \mathrm{kDa}$, corresponding to syntaxins $1 \mathrm{a}$ and $1 \mathrm{~b}$; in retina, only a single band was detected at $35 \mathrm{kDa}$, probably syntaxin 1a based on its size. Anti-syntaxin 3 recognized a single $35 \mathrm{kDa}$ band in retina but nothing in brain, demonstrating that anti-syntaxin 3 does not cross-react with syntaxin 1 and that syntaxin 3 is not present at detectable levels in brain.

Immunoprecipitation of retina extract with the anti-syntaxin 3 antiserum corroborated that, like syntaxin 1, syntaxin 3 participates in a SNARE complex not only with SNAP-25 and complexin, but also with synaptobrevin. Retina extract was immunoprecipitated with anti-syntaxin 3 , and then the immunoprecipitated material was immunoblotted with antibodies against syntaxin 3, SNAP-25, and synaptobrevin (Fig. 4B). All three proteins were found to be co-immunoprecipitated with anti-syntaxin 3 .

\section{Syntaxin 3 is localized to the ribbon synapse-forming neurons in the retina}

To determine the cellular localization of the retina SNARE complex, we examined the distribution of syntaxin 3 in rat retina by light microscopic immunocytochemistry. In the outer retina, the anti-syntaxin 3 antiserum labeled the inner segments, somata, and terminals of photoreceptors (Fig. $5 A$ ). The strongest labeling was observed in the photoreceptor synaptic terminals located in the OPL. This pattern of syntaxin 3 immunostaining is very similar to that observed for SNAP-25 immunoreactivity in the outer retina (Fig. $1 B$ ). In the INL, labeling of bipolar cell somata and, in the IPL, of putative bipolar cell terminals was detected (Fig. $5 A$ ). As a control, retina sections were incubated with the preimmune serum. Apart from nonspecific labeling of photoreceptor inner segments, no immunoreactivity with photoreceptors or bipolar cells was detected (Fig. 5B).

The large, lobular, syntaxin 3-immunoreactive structures at the bottom of the IPL (Fig. 5A) resemble the axon terminals of rod bipolar cells. This was verified with double-labeling experiments using the antiserum against syntaxin 3 in combination with an antibody against an isoform of protein kinase $\mathrm{C}(\mathrm{PKC} \alpha)$ that has been shown to label rod bipolar cells and their terminals in the IPL (Greferath et al., 1990). Labeling for syntaxin 3 (Fig. 6A) was visualized with CY3 (red) fluorescence, and rod bipolar cell staining (Fig. $6 B$ ) was revealed with FITC (green) fluorescence. Comparing Figure $6 A$ with $6 B$, it is apparent that the varicose swellings of the rod bipolar cell axon terminals (Fig. $6 B$ ) correspond to many of the large immunoreactive puncta found in the IPL with the syntaxin 3 staining (Fig. 6A). There are, however, many smaller puncta that are immunoreactive for syntaxin 3 throughout the IPL of the rat retina. These other syntaxin 3-immunoreactive puncta most likely correspond to the terminals of cone bipolar cells, the other class of ribbon synapse containing bipolar cells in the retina.

\section{DISCUSSION}

The rate of synaptic vesicle exocytosis from conventional synapses has been measured at 20 vesicles/sec/synapse (Stevens and Tsujimoto, 1995). In contrast, the tonic rate of exocytosis from a single active zone in a salamander rod photoreceptor was calculated to be $>400$ vesicles/sec (Rieke and Schwartz, 1996). Similarly high rates of synaptic vesicle exocytosis have been measured in frog saccular hair cells (Parsons et al., 1994) and in goldfish bipolar cell terminals (Heidelberger et al., 1994; von Gersdorff and Matthews, 1994). Thus, the design of the ribbon synapse appears to be optimized for sustaining a high rate of neurotransmitter release. Crucial to the design are highly efficient, tightly coupled mechanisms of synaptic vesicle exo- and endocytosis. 

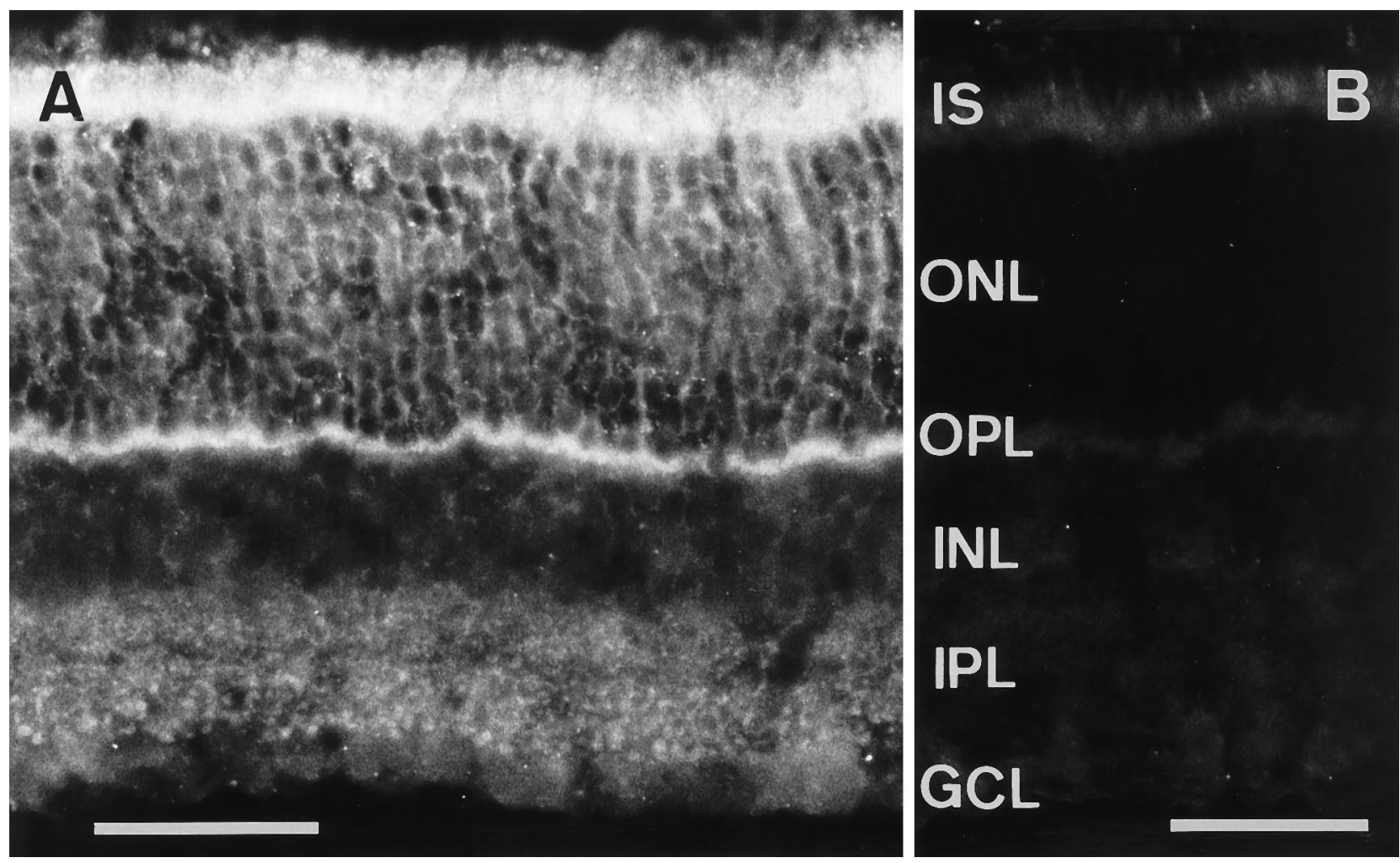

Figure 5. Vertical cryostat sections through rat retina stained with the anti-syntaxin 3 antiserum or preimmune serum. $A$, Syntaxin 3 immunoreactivity is localized to photoreceptor cells in the ONL and their terminals in the OPL, and to bipolar cells in the INL and their terminals in the IPL. $B$, No specific immunoreactivity is detectable using the preimmune serum. Abbreviations as in Figure 1. Scale bars, $40 \mu \mathrm{m}$.

Here we show that cells forming ribbon and conventional synapses in the retina express distinct forms of syntaxin, a protein central to synaptic vesicle exocytosis. Syntaxin 1 is restricted to cells forming conventional synapses (amacrine cells) (Brandstätter et al., 1996), whereas syntaxin 3 is found in cells making ribbon synapses (the photoreceptors and bipolar cells). The results from the labeling of photoreceptor terminals in the OPL (Fig. 5) and the colocalization between the staining of the rod bipolar cell terminals and the large anti-syntaxin 3-immunoreactive puncta in the IPL (Fig. 6) are strongly suggestive of the presence of syntaxin 3 at ribbon synapses in the retina. Differences in the properties of the two forms of syntaxin could be important determinants of the mode of neurotransmitter release, i.e., tonic versus phasic, from ribbon and conventional synapses, respectively.

Syntaxin 3 is 64 and $61 \%$ identical to syntaxins $1 \mathrm{a}$ and $1 \mathrm{~b}$, respectively, and shares the same overall domain structure as other members of the syntaxin family (Bennett et al., 1993), including a $\mathrm{C}$-terminal membrane anchor and several predicted coiled-coil domains likely to be involved in protein-protein interactions. We isolated syntaxin 3 from retina in a complex with SNAP-25 and an $18 \mathrm{kDa}$ protein identified as a complexin because of its high partial sequence identity with complexins 1 and 2 (Fig. 3) (McMahon et al., 1995). Complexins 1 and 2 appear to be highly conserved across species, with the complexin 2 sequence being $100 \%$ identical in rat, mouse, and human (McMahon et al., 1995). Thus, although the retina sequence was obtained from a bovine protein, it is likely to represent a novel member of the complexin family. It will be of interest to determine whether there is any specificity in the binding of different complexins to different syntaxins.
Complexins 1 and 2 were identified by co-immunoprecipitation with syntaxin 1 (McMahon et al., 1995). Because the immunoprecipitated material also contained SNAP-25 and synaptobrevin (McMahon et al., 1995), complexins were proposed to bind to the SNAP receptor-core complex consisting of synaptobrevin, syntaxin 1, and SNAP-25 (McMahon and Südhof, 1995). We have shown that syntaxin 3 can be immunoprecipitated with both complexin and synaptobrevin, but our data do not indicate whether the association of complexin and synaptobrevin with syntaxin 3 is mutually exclusive. The broad cellular distributions of SNAP-25, syntaxin 1 , and complexins 1 and 2, compared to the strictly synaptic localization of synaptobrevin (McMahon et al., 1995), are consistent with complexin interacting with syntaxin and SNAP-25 in the absence of synaptobrevin.

Synaptobrevin was found to be associated with syntaxin 3 in the retina. It was detected using antibodies against synaptobrevin 2 that do not cross-react with synaptobrevin 1 . This suggests that synaptobrevin 2 may occur in ribbon synapses; however, in vitro binding assays using recombinant proteins have shown that synaptobrevin 2 binds tightly to syntaxin 1a and with low affinity to syntaxin 4 , but not to syntaxins 2 and 3 (Pevsner et al., 1994a). These observations led to the proposal that the specificity of membrane-vesicle fusion is determined in part by the pairing of each syntaxin with a particular synaptobrevin partner in an interaction that is enhanced by SNAP-25 (Bennett and Scheller, 1994). If the interaction between synaptobrevin and syntaxin is of physiological significance, then the present results suggest either that synaptobrevin 2 does bind to syntaxin 3 in vivo or that a different synaptobrevin isoform is expressed in the retina that cross-reacts with the synaptobrevin 

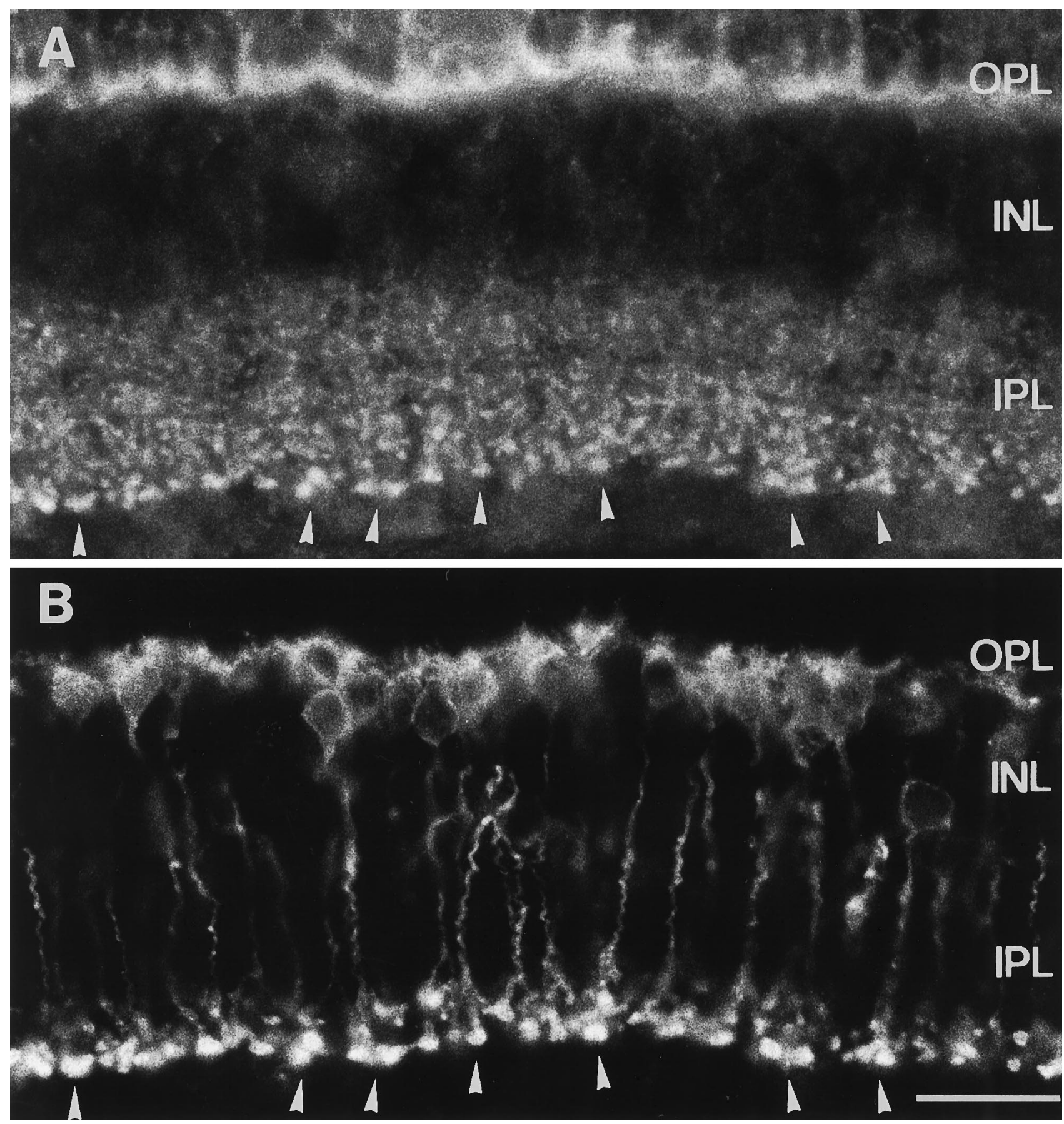

Figure 6. Vertical cryostat section through rat retina double-immunolabeled for syntaxin 3 and PKC. $A$, Strong staining in the OPL and weaker staining in the IPL are visible with the antiserum against syntaxin 3. $B$. Immunostained rod bipolar cells and a few amacrine cells are visible with the antibody against PKC. Many immunoreactive terminals of putative bipolar cells in the IPL in $A$ (arrowheads) colocalize with the stained bipolar cell terminals in $B$ (arrowheads). Abbreviations as in Figure 1. Scale bar, $20 \mu \mathrm{m}$.

2 antibodies. Alternatively, the association of synaptobrevin 2 with the syntaxin 3 complex could be mediated by SNAP-25, because strong binding between recombinant synaptobrevin 2 and recombinant SNAP-25 has been observed in vitro (Pevsner et al., 1994a).

Neurotransmitter release from ribbon synapses is exquisitely sensitive to changes in membrane potential. For instance, detection of a single photon by a rod photoreceptor hyperpolarizes the membrane by only $200 \mu \mathrm{V}$, yet the event is reliably transmitted (Capovilla et al., 1987). Changes in the membrane potential are translated into changes in the presynaptic calcium concentration. For synaptic vesicle exocytosis at a ribbon synapse to reliably follow subtle changes in the calcium concentration, close apposition of the calcium channels and sites of synaptic vesicle fusion seems likely. Indeed, association of docked vesicles and calcium channels may occur in conventional synapses, because syntaxin 1 has been demonstrated to bind to N-, P-, and Q-type calcium channels in vitro (Sheng et 
al., 1994; Bezprozvanny et al., 1995; El Far et al., 1995; MartinMoutot et al., 1996). In addition to positioning synaptic vesicles at sites where calcium levels would rise most steeply and to the highest levels, the interaction with syntaxin 1 actually modulates the gating properties of the calcium channels (Bezprozvanny et al., 1995). Ribbon synapses in retinal photoreceptors, bipolar cells, pinealocytes, and saccular hair cells do not have $\mathrm{N}-, \mathrm{P}-$, or Q-type calcium channels but L-type channels instead (Fuchs et al., 1990; Heidelberger and Matthews, 1992; Rieke and Schwartz, 1994; Chik et al., 1995). Thus, it will be of interest to find out whether syntaxin 3 binds to L-type calcium channels and thereby links sites of vesicle fusion to sites of calcium entry in ribbon synapses.

Syntaxin 1 has high-affinity binding sites for many of the other proteins involved in synaptic vesicle exocytosis at conventional synapses and is likely to constitute a key locus for the regulation of exocytosis. Some of these proteins bind syntaxin 1 independently of one another, as is the case for complexin and synaptotagmin (McMahon et al., 1995). Other proteins, however, interact with syntaxin 1 in a highly interdependent manner. For example, the binding of either complexin or synaptotagmin to syntaxin 1 can be displaced by $\alpha$-SNAP (Söllner, 1993; McMahon et al., 1995); likewise, the binding of SNAP-25 or synaptobrevin and n-Sec1 is mutually exclusive (Pevsner et al., 1994a). For some proteins, interaction with syntaxin 1 is synergistic. For example, synaptobrevin binds more tightly to syntaxin 1 and SNAP-25 together than to either protein alone (Pevsner et al., 1994a). The presence of syntaxin 3 in neurons forming ribbon synapses raises the possibility that differences between ribbon and conventional synapses exist at several points in the fusion reaction. A biochemical comparison of the interactions of syntaxins 1 and 3 with other synaptic proteins could yield important information about how the exocytotic machinery of ribbon synapses is tailored for tonic neurotransmitter release.

\section{REFERENCES}

Barnstable CJ, Hofstein R, Akagawa K (1985) A marker of early amacrine cell development in rat retina. Dev Brain Res 20:286-290.

Bennett MK, Scheller RH (1994) Molecular correlates of synaptic vesicle docking and fusion. Curr Opin Neurobiol 4:324-329.

Bennett MK, Garcia-Arraras JE, Elferink LA, Peterson K, Fleming AM, Hazuka CD, Scheller RH (1993) The syntaxin family of vesicular transport receptors. Cell 74:863-873.

Bezprozvanny I, Scheller RH, Tsien RW (1995) Functional impact of syntaxin on gating of $\mathrm{N}$-type and Q-type calcium channels. Nature 378:623-626.

Brandstätter JH, Wässle H, Betz H, Morgans CW (1996) The plasma membrane protein SNAP-25, but not syntaxin, is present at photoreceptor and bipolar cell synapses in the rat retina. Eur $\mathrm{J}$ Neurosci 8:823-828.

Capovilla M, Hare WA, Owen WG (1987) Voltage gain of signal transfer from retinal rods to bipolar cells in the tiger salamander. J Physiol (Lond) 391:125-140.

Chik CL, Liu Q, Li B, Karpinski E, Ho AK (1995) cGMP inhibits L-type $\mathrm{Ca}^{2+}$ channel currents through protein phosphorylation in rat pinealocytes. J Neurosci 15:3104-3109.

Devries S, Baylor D (1993) Synaptic circuitry of the retina and olfactory bulb. Cell 72:139-149.

Dowling (1987) The retina, an approachable part of the brain. Cambridge: Harvard UP.

Dubin MW (1970) The inner plexiform layer of the vertebrate retina: a quantitative and comparative electron microscopic analysis. J Comp Neurol 140:479-506.

El Far O, Charvin N, Leveque C, Martin-Moutot N, Takahashi M, Seagar MJ (1995) Interaction of a synaptobrevin (VAMP)-syntaxin complex with presynaptic calcium channels. FEBS Lett 361:101-105.
Fischer LJ (1979) Development of synaptic arrays in the inner plexiform layer of neonatal mouse retina. J Comp Neurol 187:359-372.

Fuchs PA, Evans MG, Murrow BW (1990) Calcium currents in hair cells isolated from the cochlea of the chick. J Physiol (Lond) 429:553-568.

Garcia EP, Gatti E, Butler M, Burton J, De Camilli P (1994) A rat brain Sec1 homologue related to Rop and Unc18 interacts with syntaxin. Proc Natl Acad Sci USA 91:2003-2007.

Greferath U, Grünert U, Wässle H (1990) Rod bipolar cells in the mammalian retina show protein kinase C-like immunoreactivity. J Comp Neurol 301:433-442.

Hata Y, Slaughter CA, Südhof TC (1993) Synaptic vesicle fusion complex contains unc-18 homologue bound to syntaxin. Nature 366:347-351.

Heidelberger R, Matthews G (1992) Calcium influx and calcium currents in single synaptic terminals of goldfish retinal bipolar neurons. J Physiol (Lond) 447:235-256.

Heidelberger R, Heinemann C, Neher E, Matthews G (1994) Calcium dependence of the rate of exocytosis in a synaptic terminal. Nature 371:513-515.

Kee Y, Scheller R (1996) Localization of synaptotagmin-binding domains on syntaxin. J Neurosci 16:1975-1981.

Laemmli UK (1970) Cleavage of structural proteins during the assembly of the head of bacteriophage T4. Nature 227:680-685.

Li C, Ullrich B, Zhang JZ, Anderson RGW, Brose N, Südhof TC (1995) $\mathrm{Ca}^{2+}$-dependent and -independent activities of neural and non-neural synaptotagmins. Nature 375:594-599.

Linberg KA, Fisher SK (1986) An ultrastructural study of interplexiform cell synapses in the human retina. J Comp Neurol 243:561-576.

Linberg KA, Fisher SK (1988) Ultrastructural evidence that horizontal cell axon terminals are presynaptic in the human retina. J Comp Neurol 268:281-297.

Mandell JW, Townes-Anderson E, Czernik AJ, Cameron R, Greengard P, De Camilli P (1990) Synapsins in the vertebrate retina: absence from ribbon synapses and heterogeneous distribution among conventional synapses. Neuron 5:19-33.

Mandell JW, Czernik AJ, De Camilli P, Greengard P, Townes-Anderson E (1992) Differential expression of synapsin I and II among rat retinal synapses. J Neurosci 12:1736-1749.

Martin-Moutot N, Charvin N, Leveque C, Sato K, Nishiki T, Kozaki S, Takahashi M, Seagar M (1996) Interaction of SNARE complexes with $\mathrm{P} / \mathrm{Q}$-type calcium channels in rat cerebellar synaptosomes. J Biol Chem 271:6567-6570.

McMahon HT, Südhof TC (1995) Synaptic core complex of synaptobrevin, syntaxin, and SNAP-25 forms high affinity $\alpha$-SNAP binding site. J Biol Chem 270:2213-2217.

McMahon HT, Missler M, Li C, Südhof TC (1995) Complexins: cytosolic proteins that regulate SNAP receptor function. Cell 83:111-119.

O'Connor VM, Shamotienko O, Grishin E, Betz H (1993) On the structure of the "synaptosecretosome": evidence for a neurexin/ synaptotagmin/syntaxin/calcium channel complex. FEBS Lett 326:255-261.

Parsons TD, Lenzi D, Almers W, Roberts WM (1994) Calcium-triggered exocytosis and endocytosis in an isolated presynaptic cell. Neuron 13:875-883.

Pellegrini LL, O'Connor V, Lottspeich F, Betz H (1995) Clostridial neurotoxins compromise the stability of a low energy SNARE complex mediating NSF activation of synaptic vesicle fusion. EMBO J 14:4705-4713.

Pevsner J, Hsu SC, Braun JEA, Calakos N, Ting AE, Bennett MK, Scheller R (1994a) Specificity and regulation of a synaptic vesicle docking complex. Neuron 13:353-361.

Pevsner J, Hsu SC, Scheller RH (1994b) n-Sec1: a neural-specific syntaxin-binding protein. Proc Natl Acad Sci USA 91:1445-1449.

Pieribone VA, Shupliakov O, Brodin L, Hilfiker-Rothenfluh S, Czernik AJ, Greengard P (1995) Distinct pools of synaptic vesicles in neurotransmitter release. Nature 375:493-497.

Rao-Mirotznik R, Harkins AB, Buchsbaum G, Sterling P (1995) Mammalian rod terminal: architecture of a binary synapse. Neuron 14:561-569.

Rieke F, Schwartz EA (1994) A cGMP-gated current can control exocytosis at cone synapses. Neuron 13:868-873.

Rieke F, Schwartz EA (1996) Asynchronous transmitter release: control of exocytosis and endocytosis at the salamander rod synapse. J Physiol (Lond) 493:1-8.

Rosahl TW, Spillane D, Missler M, Herz J, Selig DK, Wolf JR, Hammer RE, Malenka RC, Südhof TC (1995) Essential functions of synapsins I and II in synaptic vesicle regulation. Nature 375:488-493. 
Sheng ZH, Rettig J, Takahashi M, Catterall W (1994) Identification of a syntaxin-binding site on N-type calcium channels. Neuron 13:1303-1313.

Söllner T, Bennett M, Whiteheart SW, Scheller RH, Rothman JE (1993) A protein assembly-disassembly pathway in vitro that may correspond to sequential steps of synaptic vesicle docking, activation, and fusion. Cell 75:409-418.

Stevens CF, Tsujimoto T (1995) Estimates for the pool size of releasable quanta at a single central synapse and for the time required to refill the pool. Proc Natl Acad Sci USA 92:846-849.

Südhof TC (1995) The synaptic vesicle cycle: a cascade of protein-protein interactions. Nature 375:645-653.

Takahashi T, Momiyama A (1993) Different types of calcium channels mediate central synaptic transmission. Nature 366:156-158.
Turner TJ, Adams ME, Dunlap K (1993) Multiple calcium channel types coexist to regulate synaptosomal neurotransmitter release. Proc Natl Acad Sci USA 90:9518-9522.

Ullrich B, Südhof TC (1994) Distribution of synaptic markers in the retina: implications for synaptic vesicle traffic in ribbon synapses. J Physiol (Paris) 88:249-257.

von Gersdorff H, Matthews G (1994) Dynamics of synaptic vesicle fusion and membrane retrieval in synaptic terminals. Nature 367:735-739.

Wheeler DB, Randall A, Tsien RW, Ullrich B, Südhof TC (1994) Roles of N-type and Q-type $\mathrm{Ca}^{2+}$ channels in supporting hippocampal synaptic transmission. Science 264:107-111.

Yoshida A, Oho C, Omori A, Kuwahara R, Ito T, Takahashi M (1992) HPC-1 is associated with synaptotagmin and $\omega$-conotoxin receptor. J Biol Chem 267:24925-24928. 